\title{
Physical activity and psychological well-being in obese pregnant and postpartum women attending a weight-gain restriction programme
}

\author{
Ing-Marie Claesson, Sofia Klein, Gunilla Sydsjö and Ann Josefsson
}

\section{Linköping University Post Print}

N.B.: When citing this work, cite the original article.

Original Publication:

Ing-Marie Claesson, Sofia Klein, Gunilla Sydsjö and Ann Josefsson, Physical activity and psychological well-being in obese pregnant and postpartum women attending a weight-gain restriction programme, 2013, Midwifery.

http://dx.doi.org/10.1016/j.midw.2012.11.006

Copyright: Elsevier http://www.elsevier.com/

Postprint available at: Linköping University Electronic Press http://urn.kb.se/resolve?urn=urn:nbn:se:liu:diva-90055 
Ing-Marie Claesson RNM, PhD, Sofia Klein MD, Gunilla Sydsjö PhD, Ann Josefsson MD, $\mathrm{PhD}$

Division of Obstetrics and Gynecology, Department of Clinical and Experimental Medicine, Faculty of Health Sciences, Linköping University, Department of Obstetrics and Gynecology in Linköping, County Council of Östergötland, Linköping, Sweden

\section{PhysicAl ACTIVITY AND PSYCHOLOGICAL WELL-BEING IN OBESE PREGNANT AND POSTPARTUM WOMEN ATTENDING A WEIGHT-GAIN RESTRICTION PROGRAM}

Correspondence:

Ing-Marie Claesson

Division of Obstetrics and Gynaecology

Department of Clinical and Experimental Medicine

Faculty of Health Sciences

Linköping University

SE - 58183 Linköping, Sweden

Tel: + 4610 1032923; fax: +4613148156

Email: Ing-Marie.Claesson@liu.se 


\begin{abstract}
Objective: The objective of the study was to compare the differences in psychological wellbeing and quality of life during pregnancy and postpartum of obese physically active women and obese physically inactive women enrolled in a weight gain restriction program. We also wanted to explore whether physical activity influences weight change or health status during pregnancy.
\end{abstract}

Design: A prospective intervention study.

Setting: Antenatal care clinic.

Participants: A total of 74 obese pregnant women in a physically active group and 79 obese women in a physically inactive group.

Measurements: The women kept diaries of their physical activity during pregnancy and answered the Beck Anxiety Inventory, the Edinburgh Postnatal Depression Scale and Medical Study Short-Form Health Survey in gestational week 15 and 35 and 11 weeks postpartum. Physical activity was measured in metabolic equivalents.

Findings: The physically active women experienced fewer depressive symptoms and estimated an improved quality of life during their pregnancies as measured by physical functioning, bodily pain, social functioning, role limitations due to emotional problems and general mental health as compared with the physically inactive women. There were no differences between the groups in gestational weight gain or weight change from early pregnancy to postpartum or in prevalence of complications.

Key conclusions: Physical activity among obese pregnant women provides better psychological wellbeing and improved quality of life, but does not prevent weight change. Implications for practice: Staff at Antenatal Care Clinics that face obese pregnant women, should encourage and emphasize the benefits of being physically active throughout pregnancy.

\title{
Keywords
}

Physical activity, obesity, pregnancy, depression, anxiety, quality of life 


\section{Introduction}

Regular physical exercise is associated with better physical and mental health (Swedish National Institute of Public Health, 2010). In Sweden, as well as in the US, the general recommendation for adults, including pregnant women, for physical activity is at least 30 minutes of moderate intensity on most days of the week (Swedish National Institute of Public Health, 2010, Pate et al., 1995, Bell, 2006). Two Norwegian studies investigated the level of physical activity among pregnant women and reported levels of activity for regular exercisers of $81 \%, 69 \%$ and $11 \%$ before pregnancy, in the first and in the third trimester respectively, whereas a British study found that $65 \%$ of women in gestational week 13 achieved at least 30 minutes moderate or vigorous daily activity (Haakstad et al., 2007, McParlin et al., 2010, Haakstad et al., 2009).

Some recent studies have investigated physical activity during pregnancy and the first year postpartum and report an association between physical activity and a lower risk of hypertensive complications, fewer symptoms of nausea, vomiting and low back pain (Martin and Brunner Huber, 2010, Foxcroft et al., 2011). Furthermore, physical activity during pregnancy was associated with an improved health-related quality of life, lower postpartum Body Mass Index (BMI) and fewer depressive symptoms (Montoya Arizabaleta et al., 2010, Vernon et al., 2010). In a current meta-analysis by Streuling et al. (2010) with randomized controlled trials on healthy pregnant women, with increased physical activity as the only intervention, the authors conclude that physical exercise during pregnancy might be successful in restricting gestational weight gain (Streuling et al., 2010).

In many intervention studies with the aim of preventing excessive gestational weight gain, recommendations or advisories concerning physical activity and exercise were given (Polley et al., 2002, Olson et al., 2004, Kinnunen et al., 2007, Artal et al., 2007, Asbee et al., 2009, Guelinckx et al., 2010, Phelan et al., 2011). Only a few of these studies have reported outcomes (Polley et al., 2002, Kinnunen et al., 2007, Guelinckx et al., 2010). Polley et al. (2002) and Kinnunen et al. (2007) found no difference in exercise level between the intervention group and the control group, whereas in the study of Guelinckx et al. (2010) physical activity decreased during pregnancy in both the two intervention groups and in the control group.

We have previously shown, in an intervention study among obese pregnant women, that structured motivational and behavioral treatment strategies during pregnancy were effective in minimizing the gestational weight gain to less than $7 \mathrm{~kg}$ (Claesson et al., 2008) and at followup two years after child birth, that the subgroup of women in the intervention group who 
gained $<7 \mathrm{~kg}$ during pregnancy, had a lower weight than corresponding women in the control group (Claesson et al., 2010).

Whether regular physical exercise together with a weight gain restriction intervention program has an additive effect on psychological well-being or in preventing weight gain has been little investigated.

The primary aim of our study was to compare two groups of obese pregnant women participating in a weight gain restriction program, one whose members exercised regularly during pregnancy, the other whose members did not. The comparisons concerned differences in psychological wellbeing and quality of life during pregnancy and postpartum. The secondary aim was to explore whether physical activity influenced weight change from early pregnancy to postpartum or health status during pregnancy. 


\section{Methods}

Sweden has a very well-attended maternal health care system, which reaches almost $100 \%$ of pregnant women and is free of charge. The expectant mothers receive care at Antenatal Care clinics and normally make seven to nine visits with a midwife and, if needed, additional visits with an obstetrician.

\section{$\underline{\text { Subjects }}$}

During November 2003- December 2005 all obese $\left(B M I \geq 30 \mathrm{~kg} / \mathrm{m}^{2}, \mathrm{n}=317\right)$ pregnant women who registered at the Antenatal Care clinic in the city of Linköping and surroundings were offered the chance to participate in an intervention study with the aim of minimizing gestational weight gain to less than $7 \mathrm{~kg}$. The exclusion criteria were inability to understand Swedish, a diagnosis of pre-pregnant diabetes, thyroid dysfunction or a psychiatric disease treated with neuroleptic drugs, and 45 women were therefore excluded from participation. Twenty women moved out of the area during pregnancy, and 13 had early spontaneous or legal abortion and were also excluded. Of the 230 remaining women, 70 women chose not to participate and five dropped out during pregnancy. Finally, 155 women $(67.4 \%)$ completed the study. For more information about the study, see Claesson et al. (2008). All women were instructed to keep a diary of their physical exercise during the whole pregnancy. They were also instructed to register every activity that entailed activity with the intensity of a brisk walk or greater, and they were encouraged to perform such activities at least 30 minutes a day. In this study we defined physical activity as being habitual when performed with at least moderate intensity three times weekly or more during at least 15 weeks of pregnancy. Out of the 155 women, 74 women with singleton pregnancies reported making physical activity a habit during pregnancy, and these 74 constituted the physically active (PA) group. The remaining 79 women with singleton pregnancies got the same recommendations concerning physical activity during pregnancy, but chose, according to their diaries, to exercise below the recommended amount regarding intensity, frequency or duration. Thus, these 79 constituted the physically inactive (PIA) group.

\section{$\underline{\text { Measures }}$}

The intensity of physical activity was measured by using the entity of metabolic equivalents as a wide range of activities have been reported (Ainsworth et al., 2000). Metabolic equivalents make possible a structured classification system for coding physical activity by type and intensity. An activity with energy expenditure of 3 metabolic equivalents or more was considered as moderate intensity and corresponds to a brisk walk (Pate et al., 1995). 
Symptoms of depression and anxiety were measured with Edinburgh Postnatal Depression Scale (EPDS) and Beck Anxiety Inventory (BAI) and quality of life was measured with Medical Outcome Study Short-Form Health Survey (SF-36 [version 1]) at three times during and after pregnancy, in gestational week 15 and 35 and finally 11 weeks postpartum. EPDS is a 10-item self-report scale assessing symptoms of depression such as dysphoric mood, anxiety, and feeling of guilt, suicidal ideas and "not coping". Each item is scored on a four point scale (0-3) and rates the intensity of depressive symptoms during the previous 7 days. The higher the score, the greater the number of depressive symptoms. The scale is specifically designed to screen for postpartum depression but can also be used as a valid measure of dysphoria through the various stages of pregnancy and the puerperium (Cox et al., 1987). The validity of the Swedish version has been tested (Rubertsson et al., 2011).

BAI was used to measure the severity of anxiety (Beck et al., 1988). The BAI consists of a 21-item self-report inventory where each item describes a common symptom of anxiety. The BAI discriminate anxiety from depression (Beck et al., 1988). The respondent was asked to rate each symptom over the preceding week on a four point scale (0-3). Scores of 0-7 reflect minimal anxiety, 8-15 mild anxiety, 16-25 moderate anxiety and score of 26-63 indicate severe anxiety (Beck and Steer, 2005). The BAI is investigated and validated in non-clinicalsamples (Nordhagen, 2001).

SF-36 groups 36 items into eight health concepts which assesses: limitations in physical activities because of health problems, limitations in social activities because of physical or emotional problems, limitations in normal role activities because of physical health problems, bodily pain, general mental health (psychological distress and well-being), limitations in ordinary role activities because of emotional problems, vitality (energy and fatigue) and general health problems (Ware and Sherbourne, 1992). An additional single item concerns reported health transitions during the preceding year. Physical and mental components summaries are calculated separately. The form is designed for use in clinical practice and research and a high score represents a better health-related quality of life. It has been translated into Swedish and shows good construct validity and high reliability across general populations in Sweden (Sullivan et al., 1995).

\section{$\underline{\text { Statistics }}$}

All analyses were performed using the IBM SPSS program, version 19.0 (IBM Corp., Armonk, NY, USA). Statistical significance was defined as (two-sided) $\mathrm{p} \leq 0.05$. Group differences were estimated by using the chi-square test on categorical variables and the 
Student's $t$ test on continuous, normally distributed variables. Furthermore, to make a more comprehensive assessment of group differences, linear regressions were performed with the three measurements as dependent variables. The grouping variable has been adjusted for socio-demographic variables (age, parity, marital status, smoking habits, socioeconomic factors, occupational status and BMI).

The study was approved by the Regional Ethical Review Board in Linköping 


\section{Findings}

Background characteristics at the first visit at the antenatal care clinic are displayed in Table 1. There was a significant difference between the PA- and PIA groups in self-reported physical activity concerning intensity.

Table 2 shows the distribution of the mean value of the total score of EPDS, measuring depressive symptoms in gestational week 15 and 35 and 11 weeks postnatal. There was a significant difference between the two groups for all measurements. The women in the PA group had fewer depressive symptoms compared with the women in the PIA group. After adjustment for socio-demographic characteristics there was still a significant difference during pregnancy. Comparison of the mean value of the total score of BAI, measuring symptoms of anxiety, shows no differences between the groups in any of the measurements (data not shown).

Analysis of the eight health concepts in SF-36 shows differences between the two groups (Table 3). The women in the PA group estimated in gestational week 35 and at 11 weeks postpartum that they had a significantly better capacity to perform all types of physical activities including the most vigorous without limitations due to health, compared with the women in the PIA group. There was also a significant difference in gestational week 35 concerning social functioning, bodily pain and role limitations due to emotional problems. The women in the PA group estimated having a better capacity to perform normal social activities without interference due to physical or emotional problems during the preceding four weeks, fewer problems with daily activities as a result of emotional problems during the preceding four weeks and less pain or limitations due to pain during the preceding four weeks, compared with the women in the PIA group. Furthermore, there was a significant difference in assessment of general mental health in gestational week 15 and 35 and general health perceptions at the measurement in gestational week 15. The women in the PA group expressed feelings of peacefulness, happiness and calm to a greater extent than women in the PIA group. They had also expressed to a greater extent a belief that their personal health was perfect, than did members of the PIA group. Concerning mental component summary there was a significant difference between the two groups in assessment at gestational week 35 . The women in the PA group reported mental quality of life that was seen on analysis to be better than the women in the PIA group. After adjustment for socio-demographic characteristics there was still a significant difference between the two groups in gestational week 35 concerning physical functioning $(\mathrm{p}=0.016)$, bodily pain $(\mathrm{p}=0.038)$, social functioning $(\mathrm{p}=.008)$, role limitation due to emotional problems $(\mathrm{p}=0.009)$ and mental component 
summary $(\mathrm{p}=0.018)$ and furthermore regarding general mental health both in gestational week 15 and 35 ( $\mathrm{p}=0.026$ and $\mathrm{p}=0.020$ respectively).

The fluctuations within the three scales, assessed between gestational week 15 and 35 and between gestational week 15 and 11 weeks postpartum, did not show any differences either within the group or between the groups (data not shown).

There were no differences between the PA group and the PIA group in weight gain during pregnancy or weight change from early pregnancy to the postnatal check-up at 11 weeks postpartum. Neither were there any differences in prevalence of preeclampsia, lumbar and pelvic pain, premature contractions and hyperemesis between the groups during pregnancy (data not shown). 


\section{Discussion}

In this prospective intervention study we found that the PA group had fewer depressive symptoms during pregnancy and postnatally, compared with the PIA group. Furthermore, the PA group reported better capacity, fewer pain and problems in five of the eight health concepts measured by SF-36 in gestational week 35 than did women in the PIA group. Physical activity did not affect the gestational weight gain, health status during pregnancy or the weight postpartum.

It has been widely reported that physical activity, for a general population, has a positive impact on well-being and quality of life (Swedish National Institute of Public Health, 2010). Our findings confirm that this statement also is true for obese pregnant physically active women. However, from another point of view, one can speculate if the difference in physical activity between the two groups depends on a difference in mental health in general. A woman with depressive symptom may have great difficulties to find motivation to begin or to continue physical activity. In the original intervention study, aiming to minimize the gestational weight gain by supporting a change of lifestyle factors, we reported a significantly lower gestational weight gain and a lower weight at the postpartum check-up in the intervention group, compared with the control group (Claesson et al., 2008). In this subsample, encompassing only women from the intervention group, there was no difference in weight gain or weight change between the PA- and PIA group. There were significant differences between the two study groups in mean value of total score of EPDS and in two of the eight health concepts in SF-36, already in gestational week 15. The women in the PIA group had more symptoms of depression and assessed a lesser quality of life regarding general health perception and general mental health, compared with the PA group. It is possible that pre-pregnancy symptoms of depression and/or a worse health influenced the motivation and opportunity to being physical active.

Our results on mental health are in accordance with findings in the study by Montoya Arizabaleta et al. (2010) which randomized 64 nulliparous in an experimental group and a control group. The intervention consisted of three months supervised exercise program and showed an improved health-related quality of life, measured by SF-36, in the intervention group compared with the control group. On the other hand Vallim et al. (2011) found no difference in quality of life, evaluated by 'The World Health Organization Quality of Life BREF', between 31 non-obese pregnant women in a water aerobic program and 35 control women who received standard antenatal care (Vallim et al., 2011). At the postnatal check-up there were no differences between the PA and PIA groups, regarding depressive symptoms 
and quality of life. Our results disagree with a study by Vernon et al. (2010). That study evaluated associations between parenting stress, including depressive symptoms and light and moderate physical activity during the first year postpartum among 51 first-time mothers. Moderate physical activity was associated with fewer depressive symptoms (Vernon et al., 2010). However, there is an important difference between our study and the study by Vernon. In our study the registration of physical activity was performed during pregnancy, whereas the EPDS was answered both during pregnancy and postpartum. In the study of Vernon et al. (2010) physical activity was carried out in close connection with the measurement of depressive symptoms. We have no information about the level of postnatal physical activity in the PA and PIA groups and it is possible that the challenges associated with the new family situation result in a decrease in stamina and the availability of time for physical activity. We found no difference in gestational weight gain or weight change at the postnatal check-up between the PA group and the PIA group. This is partly in line with results in a study by Haakstad et al. (2007), who reported no differences in weight gain during the first two trimesters among women who exercised regularly during pregnancy, compared with physical inactive pregnant women. However, there was a significantly lower weight gain during the third trimester among the first-mentioned group (Haakstad et al., 2007). Vernon et al. (2010) found an association between moderate physical activity and a lower BMI postpartum. This is in contrast to our result as we could not identify any weight difference between the PA and PIA group at the postnatal check-up. None of the published intervention studies which measured level of physical activity give any information about association between physical activity and gestational weight gain (Polley et al., 2002, Kinnunen et al., 2007, Guelinckx et al., 2010). It is therefore impossible to compare different intervention studies.

We found no difference in prevalence of preeclampsia, lumbar and pelvic pain, premature contractions and hyperemesis between the groups during pregnancy. This is not in accordance with results from other studies. Foxcroft et al. (2011) found among 50 obese pregnant women, that women classified as 'exercisers', were less likely to report vomiting and nausea in gestational week 28, compared with women classified as 'non-exercisers'. Martin and Brunner Huber (2010) investigated the association between physical activity and hypertensive complications during pregnancy among around 3300 women and reported a significant doseresponse association. Pregnant women who were physically active 1-4 days per week during pregnancy ran a lower risk for developing hypertensive complications, compared with women who were physically active for less than 1 day per week. Furthermore, women who were physically active either during pregnancy or both before and during pregnancy, were less 
likely to be stricken by gestational hypertensive complications, compared with women who engaged in no physical activity during both the periods (Martin and Brunner Huber, 2010).

The strengths of this study were the prospective approach and the self-chosen type and level of physical activity. Furthermore, this study is, to our knowledge, one of the few studies measuring and reporting physical activity among obese pregnant women. The limitations were the self-reported data on physical activity, which are rarely as accurate as objective measurements such as a portable activity monitor. Another possible study design would have been the use of a pedometer.

In conclusion, physically active obese pregnant women experience fewer depressive symptoms in late pregnancy and estimate an improved quality of life, than physically inactive obese pregnant women. Physical activity did not influence gestational weight gain or weight change from early pregnancy to postpartum. The long-term effects of physical activity on well-being and quality of life after the challenging postnatal period would be an object for studies in the future.

\section{Conflict of interest statement}

None of the authors had any conflicts of interest.

\section{Acknowledgements}

This study was supported by grants from The Health Research Council of the Southeast of Sweden and ALF, County Council of Östergötland. 


\section{References}

AINSWORTH, B. E., HASKELL, W. L., WHITT, M. C., IRWIN, M. L., SWARTZ, A. M., STRATH, S. J., O'BRIEN, W. L., BASSETT, D. R., JR., SCHMITZ, K. H., EMPLAINCOURT, P. O., JACOBS, D. R., JR. \& LEON, A. S. (2000) Compendium of physical activities: an update of activity codes and MET intensities. Med Sci Sports Exerc, 32, S498-504.

ARTAL, R., CATANZARO, R. B., GAVARD, J. A., MOSTELlO, D. J. \& FRIGANZA, J. C. (2007) A lifestyle intervention of weight-gain restriction: diet and exercise in obese women with gestational diabetes mellitus. Appl Physiol Nutr Metab, 32, 596-601.

ASBEE, S. M., JENKINS, T. R., BUTLER, J. R., WHITE, J., ELLIOT, M. \& RUTLEDGE, A. (2009) Preventing excessive weight gain during pregnancy through dietary and lifestyle counseling: a randomized controlled trial. Obstet Gynecol, 113, 305-12.

BECK, A. T., EPSTEIN, N., BROWN, G. \& STEER, R. A. (1988) An inventory for measuring clinical anxiety: psychometric properties. J Consult Clin Psychol, 56, 8937.

BECK, A. T. \& STEER, R. A. (2005) BAI Beck Anxiety Inventory Manual Swedish Version, Stockholm, Psykologiförlaget

BELL (2006) The Royal College of Obstetricians and Gynaecologists:Exercise in Pregnancy (RCOG Statement 4)

CLAESSON, I. M., SYDSJO, G., BRYNHILDSEN, J., BLOMBERG, M., JEPPSSON, A., SYDSJO, A. \& JOSEFSSON, A. (2010) Weight after childbirth: a 2-year follow-up of obese women in a weight-gain restriction program. Acta Obstet Gynecol Scand, 90, 103-10.

CLAESSON, I. M., SYDSJO, G., BRYNHILDSEN, J., CEDERGREN, M., JEPPSSON, A., NYSTROM, F., SYDSJO, A. \& JOSEFSSON, A. (2008) Weight gain restriction for obese pregnant women: a case-control intervention study. BJOG, 115, 44-50.

COX, J. L., HOLDEN, J. M. \& SAGOVSKY, R. (1987) Detection of postnatal depression. Development of the 10-item Edinburgh Postnatal Depression Scale. Br J Psychiatry, 150, 782-6.

FOXCROFT, K. F., ROWLANDS, I. J., BYRNE, N. M., MCINTYRE, H. D. \& CALLAWAY, L. K. (2011) Exercise in obese pregnant women: the role of social factors, lifestyle and pregnancy symptoms. BMC Pregnancy Childbirth, 11, 4.

GUELINCKX, I., DEVLIEGER, R., MULLIE, P. \& VANSANT, G. (2010) Effect of lifestyle intervention on dietary habits, physical activity, and gestational weight gain in obese pregnant women: a randomized controlled trial. Am J Clin Nutr, 91, 373-80.

HAAKSTAD, L. A., VOLDNER, N., HENRIKSEN, T. \& BO, K. (2007) Physical activity level and weight gain in a cohort of pregnant Norwegian women. Acta Obstet Gynecol Scand, 86, 559-64.

HAAKSTAD, L. A., VOLDNER, N., HENRIKSEN, T. \& BO, K. (2009) Why do pregnant women stop exercising in the third trimester? Acta Obstet Gynecol Scand, 88, 126775.

KINNUNEN, T. I., PASANEN, M., AITTASALO, M., FOGELHOLM, M., HILAKIVICLARKE, L., WEIDERPASS, E. \& LUOTO, R. (2007) Preventing excessive weight gain during pregnancy - a controlled trial in primary health care. Eur J Clin Nutr, 61, 884-91.

MARTIN, C. L. \& BRUNNER HUBER, L. R. (2010) Physical activity and hypertensive complications during pregnancy: findings from 2004 to 2006 North Carolina Pregnancy Risk Assessment Monitoring System. Birth, 37, 202-10. 
MCPARLIN, C., ROBSON, S. C., TENNANT, P. W., BESSON, H., RANKIN, J., ADAMSON, A. J., PEARCE, M. S. \& BELL, R. (2010) Objectively measured physical activity during pregnancy: a study in obese and overweight women. BMC Pregnancy Childbirth, 10, 76.

MONTOYA ARIZABALETA, A. V., OROZCO BUITRAGO, L., AGUILAR DE PLATA, A. C., MOSQUERA ESCUDERO, M. \& RAMIREZ-VELEZ, R. (2010) Aerobic exercise during pregnancy improves health-related quality of life: a randomised trial. $J$ Physiother, 56, 253-8.

NORDHAGEN, T. (2001) Beck Anxiety Inventory: Translation and validation of a Norwegian version.

OLSON, C. M., STRAWDERMAN, M. S. \& REED, R. G. (2004) Efficacy of an intervention to prevent excessive gestational weight gain. Am J Obstet Gynecol, 191, 530-6.

PATE, R. R., PRATT, M., BLAIR, S. N., HASKELL, W. L., MACERA, C. A., BOUCHARD, C., BUCHNER, D., ETTINGER, W., HEATH, G. W., KING, A. C. \& ET AL. (1995) Physical activity and public health. A recommendation from the Centers for Disease Control and Prevention and the American College of Sports Medicine. JAMA, 273, 402-7.

PHELAN, S., PHIPPS, M. G., ABRAMS, B., DARROCH, F., SCHAFFNER, A. \& WING, R. R. (2011) Randomized trial of a behavioral intervention to prevent excessive gestational weight gain: the Fit for Delivery Study. Am J Clin Nutr, 93, 772-9.

POLLEY, B. A., WING, R. R. \& SIMS, C. J. (2002) Randomized controlled trial to prevent excessive weight gain in pregnant women. Int J Obes Relat Metab Disord, 26, 1494502.

RUBERTSSON, C., BORJESSON, K., BERGLUND, A., JOSEFSSON, A. \& SYDSJO, G. (2011) The Swedish validation of Edinburgh Postnatal Depression Scale (EPDS) during pregnancy. Nord $J$ Psychiatry.

STREULING, I., BEYERLEIN, A., ROSENFELD, E., HOFMANN, H., SCHULZ, T. \& VON KRIES, R. (2010) Physical activity and gestational weight gain: a meta-analysis of intervention trials. BJOG, 118, 278-84.

SULLIVAN, M., KARLSSON, J. \& WARE, J. E., JR. (1995) The Swedish SF-36 Health Survey--I. Evaluation of data quality, scaling assumptions, reliability and construct validity across general populations in Sweden. Soc Sci Med, 41, 1349-58.

SWEDISH NATIONAL INSTITUTE OF PUBLIC HEALTH, Y. F. F., AKTIVITET (2010) Physical activity in the prevention and treatment of disease, [Östersund, Sweden], Swedish National Institute of Public Health.

VALLIM, A. L., OSIS, M. J., CECATTI, J. G., BACIUK, E. P., SILVEIRA, C. \& CAVALCANTE, S. R. (2011) Water exercises and quality of life during pregnancy. Reprod Health, 8, 14.

WARE, J. E., JR. \& SHERBOURNE, C. D. (1992) The MOS 36-item short-form health survey (SF-36). I. Conceptual framework and item selection. Med Care, 30, 473-83.

VERNON, M. M., YOUNG-HYMAN, D. \& LOONEY, S. W. (2010) Maternal stress, physical activity, and body mass index during new mothers' first year postpartum. Women Health, 50, 544-62. 
Table 1. Background characteristics in the physical active- and physical inactive group at the first visit at the antenatal care clinic.

\begin{tabular}{|c|c|c|c|c|c|}
\hline & \multicolumn{2}{|c|}{$\begin{array}{l}\text { Physical active } \\
\text { group }\end{array}$} & \multicolumn{2}{|c|}{$\begin{array}{c}\text { Physical } \\
\text { inactive } \\
\text { group }\end{array}$} & \multirow[b]{2}{*}{$p$} \\
\hline & $\mathrm{n}$ & $\%$ & $\mathrm{n}$ & $\%$ & \\
\hline Age, mean (SD)* & 74 & $\begin{array}{c}29.7 \\
(4.43)\end{array}$ & 79 & $\begin{array}{c}29.6 \\
(4.58)\end{array}$ & 0.868 \\
\hline Parity** & & & & & 0.739 \\
\hline No previous children & 31 & 41.9 & 31 & 39.2 & \\
\hline$\geq 1$ previous children & 43 & 58.1 & 48 & 60.8 & \\
\hline Marital status** & & & & & 0.446 \\
\hline Married/cohabiting & 68 & 91.9 & 75 & 94.9 & \\
\hline Other family situation & 6 & 8.1 & 4 & 5.1 & \\
\hline Smoking** & & & & & 0.184 \\
\hline No & 70 & 94.6 & 70 & 88.6 & \\
\hline Yes & 4 & 5.4 & 9 & 11.4 & \\
\hline BMI $\left(\mathrm{kg} / \mathrm{m}^{2}\right)^{* *}$ & & & & & 0.130 \\
\hline $30.0-34.9$ & 53 & 71.6 & 45 & 57.0 & \\
\hline $35.0-39.9$ & 15 & 20.3 & 21 & 26.6 & \\
\hline$\geq 40.0$ & 6 & 8.1 & 13 & 16.5 & \\
\hline Socioeconomic group ${ }^{* *}$ & & & & & 0.739 \\
\hline Unskilled workers & 15 & 20.3 & 16 & 20.3 & \\
\hline Skilled workers & 22 & 29.7 & 22 & 27.8 & \\
\hline Lower white collar workers & 4 & 5.4 & 3 & 3.8 & \\
\hline Middle/high white collar workers and self-employed & 20 & 27.0 & 18 & 22.8 & \\
\hline Students & 9 & 12.2 & 10 & 12.7 & \\
\hline Unknown & 4 & 5.4 & 10 & 12.7 & \\
\hline Occupation $* *$ & & & & & 0.083 \\
\hline Gainfully employed & 53 & 71.6 & 46 & 58.2 & \\
\hline Not employed & 21 & 28.4 & 33 & 41.8 & \\
\hline \multicolumn{6}{|l|}{$\begin{array}{l}\text { Self-reported physical activity before the study } \\
\text { inclusion** }\end{array}$} \\
\hline Frequency; $\geq 3$ times weekly & & & & & 0.317 \\
\hline Yes & 48 & 64.9 & 45 & 57.0 & \\
\hline No & 26 & 35.1 & 34 & 43.0 & \\
\hline Duration; $\geq 30$ minutes daily & & & & & 0.055 \\
\hline Yes & 47 & 63.5 & 38 & 48.1 & \\
\hline No & 27 & 36.5 & 41 & 51.9 & \\
\hline Intensity; $\geq$ a brisk walk & & & & & 0.040 \\
\hline
\end{tabular}


* Student's $t$ test ** $\mathrm{X}^{2}$ test 
Table 2. The mean value of total score of Edinburgh Postnatal Depression Scale (EPDS) among obese pregnant women in the physical active- and physical inactive group and adjusted $p$-value for socio-demographic characteristics

Physical active Physical inactive group

group

\begin{tabular}{lcccccccc}
\hline EPDS Total score & $\mathrm{n}$ & mean & $\mathrm{SD}$ & $\mathrm{n}$ & mean & $\mathrm{SD}$ & $p^{*}$ & $p^{* *}$ \\
\hline Gestational week 15 & 74 & 5.5 & 3.8 & 76 & 7.1 & 5.7 & 0.009 & $0.024^{* * *}$ \\
Gestational week 35 & 68 & 4.6 & 3.7 & 73 & 6.9 & 5.1 & 0.002 & $0.004 \dagger$ \\
Postpartum week 11 & 73 & 3.8 & 3.4 & 70 & 5.3 & 4.9 & 0.033 & $0.059 \ddagger$ \\
\hline
\end{tabular}

* Students $t$ test $\quad * *$ Linear regression, adjusted for socio-demographic characteristics.

*** $p($ age $)=0.096, p($ parity $)=0.078, p($ marital status $)=0.676, p($ smoking $)=0.708, p($ socioeconomic group $)=0.476, p($ occupation $)=0.278, p($ Body Mass Index $)=0.215$.

$\dagger p($ age $)=0.060, p($ parity $)=0.015, p($ marital status $)=0.809, p($ smoking $)=0.861, p($ socio economic group $)=0.840, p($ occupation $)=0.613, p($ Body Mass Index $)=0.859$.

$\$ p($ age $)=0.060, p($ parity $)=0.121, p($ marital status $)=0.666, p($ smoking $)=0.441, p($ socioeconomic group $)=0.100, p($ occupation $)=0.889, p($ Body Mass Index $)=0.417$. 
Table 3. Mean value for each of the eight health concepts in the Medical Outcome Study Short-Form Survey (SF-36) among obese pregnant women in the physical active - and physical inactive group

\begin{tabular}{|c|c|c|c|c|c|c|c|c|c|}
\hline \multirow[b]{3}{*}{ Subscales } & \multicolumn{3}{|c|}{ Gestational week 15} & \multicolumn{3}{|c|}{ Gestational week 35} & \multicolumn{3}{|c|}{11 week postpartum } \\
\hline & $\begin{array}{l}\text { Physical active } \\
\text { group } \\
(\mathrm{n}=74)\end{array}$ & $\begin{array}{l}\text { Physical inactive } \\
\text { group } \\
(\mathrm{n}=76)\end{array}$ & & $\begin{array}{c}\text { Physical active } \\
\text { group } \\
(\mathrm{n}=68)\end{array}$ & $\begin{array}{c}\text { Physical inactive } \\
\text { group } \\
(\mathrm{n}=73)\end{array}$ & & $\begin{array}{c}\text { Physical active } \\
\text { group } \\
(\mathrm{n}=74)\end{array}$ & $\begin{array}{c}\text { Physical inactive } \\
\text { group } \\
(\mathrm{n}=70)\end{array}$ & \\
\hline & mean $(\mathrm{SD})^{*}$ & mean $(\mathrm{SD}) *$ & $p^{* *}$ & mean $(\mathrm{SD})^{*}$ & mean $(\mathrm{SD}) *$ & $p^{* *}$ & mean $(\mathrm{SD})^{*}$ & mean $(\mathrm{SD}) *$ & $p^{* *}$ \\
\hline Physical functioning & $90(13)$ & $85(18)$ & 0.062 & $66(21)$ & $58(22)$ & 0.025 & $93(10)$ & $89(15)$ & 0.036 \\
\hline $\begin{array}{l}\text { Role limitations due to physical } \\
\text { problems }\end{array}$ & $82(28)$ & $75(35)$ & 0.148 & $37(38)$ & $36(39)$ & 0.856 & $87(28)$ & $82(29)$ & 0.313 \\
\hline Bodily pain & $77(20)$ & $71(26)$ & 0.101 & $57(23)$ & $49(25)$ & 0.035 & $83(22)$ & $81(22)$ & 0.698 \\
\hline General health perceptions & $77(17)$ & $70(21)$ & 0.019 & $77(18)$ & $75(18)$ & 0.548 & $81(16)$ & $79(17)$ & 0.398 \\
\hline Social functioning & $87(19)$ & $82(23)$ & 0.180 & $86(17)$ & $76(25)$ & 0.008 & $92(16)$ & $89(16)$ & 0.510 \\
\hline $\begin{array}{l}\text { Role limitations due to emotional } \\
\text { problems }\end{array}$ & $84(27)$ & $74(38)$ & 0.052 & $91(23)$ & $75(37)$ & 0.002 & $85(32)$ & $81(34)$ & 0.471 \\
\hline Vitality & $52(20)$ & $51(20)$ & 0.785 & $54(19)$ & $49(20)$ & 0.078 & $66(17)$ & $65(19)$ & 0.731 \\
\hline General mental health & $81(13)$ & $74(19)$ & 0.010 & $82(13)$ & $76(17)$ & 0.024 & $86(13)$ & $83(15)$ & 0.245 \\
\hline $\begin{array}{l}\text { Physical component summary } \\
\text { score }\end{array}$ & $50(7)$ & $48(9)$ & 0.128 & $52(6)$ & $51(8)$ & 0.205 & $52(6)$ & $51(8)$ & 0.205 \\
\hline Mental component summary score & $47(8)$ & $45(11)$ & 0.101 & $54(7)$ & $50(12)$ & 0.011 & $50(9)$ & $49(10)$ & 0.604 \\
\hline
\end{tabular}

* Round figures are presented for clarity.

** Students $t$ test 